\title{
Solid Versus Semi-solid Fermentation of Finger Millet (Eleusine coracana L.)
}

\author{
DHAN BAHADUR KARKI * and GANGA PRASAD KHAREL
}

\author{
${ }^{1}$ Central Department of Food Technology, Institute of Science and Technology, Tribhuvan University, Nepal
}

Effects of solid versus semi-solid fermentations on the chemical and organoleptic qualities of finger millet Jand were studied. Millet was fermented under solid and semi-solid states by using defined fermentation starter and the Jand was subjected to chemical and sensory analyses. Results indicated that except on moisture and alcohol contents, semi-solid fermentation reflected a significant effect $(p<0.05)$ on the chemical characteristics of millet Jand. TSS, acidity and ester contents increased substantially in semi-solid fermentation as compared to solid-state one. Millet fermented with 50\% water addition had more than 2-folds higher total acidity than that of solid-state fermented and every 50\% increase in water addition nearly doubled the fixed acidity of the products. No remarkable improvement on the chemical and sensory quality of millet Jand was found by using semi-solid state fermentation.

Keywords: Semisolid fermentation, Defined starter, Millet Jand, Chemical and sensory quality

\section{Introduction}

Food fermentation is regarded as one of the oldest methods of food processing and preservation. More than anything else, man has known the use of microbes for the preparation of food products for thousands of years and all over the world a wide range of fermented foods and beverages contributed significantly to the diets of many people (Achi, 2005). Alcoholic beverages have played an important role in human spiritual and cultural life both in Eastern and Western societies. Unlike in Europe and Middle East, where indigenous alcoholic beverages are produced primarily from fruit, alcoholic beverages in the Asia-Pacific region are produced from cereals and serve as an important source of nutrients. Beverages vary from crystal clear (e.g. Sake) to turbid thick products e.g. Takju in Korea (Yoon, 1993). Indigenous alcoholic beverages not only add nutrients to the local diet, but also play an important part in the local custom. Traditional alcoholic beverages are offered to perform the religious practice to pray family God.

Jand is a Nepalese indigenous fermented beverage prepared by solid-state fermentation of starchy materials, particularly finger millet (Eleusine coracana), locally called as Kodo using Murcha (a traditional fermentation starter). It is one of the socially and culturally accepted mild alcoholic beverages and is presumably nutritionally superior to other alcoholic beverages, although its exact nutritional status is still unexplored. The term Murcha is a Nepali word and the different ethnic communities of the region call it by their own dialect such as Khesung by Limbu, Bharama by Tamang, Bopkha by Rai and Buth/Thanbum by Lepcha (Karki and Kharel, 2007). Kodo ko Jand is the most commonly fermented alcoholic beverages prepared from dry seeds of finger millet locally called as Kodo in the Eastern Himalayan regions of Darjeeling hills and Sikkim in India, Nepal and Bhutan. Jand is a common

*Corresponding author, E-mail: karkidhan@yahoo.com name for all alcoholic beverages in Nepal. In the oriental method of Jand making, the millet is cleaned, dehusked, winnowed, steeped in water and cooked. The cooked cereal is cooled and Murcha is added ( $1-2 \%$ by wt) followed by aerobic fermentation (biomass development) for 2-3 days and packed in earthen pot for alcoholic fermentation for at least 7 days (Thapa and Tamang, 2004).

Several traditional food fermentations e.g. Nigeriam Ogi, Japanese Sake, have been upgraded to high technology production system because of the strong research on traditional fermentation technology. But the production of indigenous fermented foods is still largely a traditional family art done in homes in a crude manner consequently the production has not increased substantially more than a cottage industry (Odufa, 1985).

Although the technology of Jand making has been practiced since antiquity, its production is still limited to home scale in Nepal. It has many shortcomings as a result of which the final product quality is the mercy of the Murcha and environmental conditions used during processing. It has a great potential of being commercialized, both in domestic and foreign markets, provided its quality (safety and nutritional value) is enhanced, which calls for a sound research and development work. Much literature is available on the traditional alcoholic fermentation of starchy raw materials under solid-state conditions using both traditional as well as defined fermentation starters (starters prepared by using pure microbial cultures isolated from traditional starters (Subba, 1985; Verma, 1991; Venkataramu and Basappa, 1993; Bhandari, 1997, Rajbhandari, 1999 and Upadhyaya, 2005) but information regarding semi-solid fermentation is scanty (Cai and Nip, 1990; Dung et al., 2007). In Nepal, all traditional cereal-based alcoholic beverages are produced under solid-state fermentation and, hence this work was undertaken aimed at investigating the effect of semi-solid fermentation on the 
quality of finger millet Jand (millet beer) using defined fermentation starter prepared from $R$. oryzae and $S$. cerevisiae.

\section{Materials and Methods}

Materials: Finger millet (brown variety) was collected from local market of Dharan. Fermentation starter was prepared using yeast (Saccharomyces cerevisiae) and mold (Rhizopus oryzae) isolated from traditional starter (Murcha) in PDA supplemented with $100 \mathrm{ppm}$ of chloramphenicol. Yeast was grown in molasses broth of $6^{\circ} \mathrm{Bx}$ TSS for 3 days at $27^{\circ} \mathrm{C}$ and kept in refrigerator until used. Mold bran was prepared by inoculating isolated mold in sterile wheat bran, incubating for 5 days at $30^{\circ} \mathrm{C}$, drying at $24^{\circ} \mathrm{C}$ for $12 \mathrm{hr}$ and then packed in sterile glass bottle. Yeast (from molasses broth) and mold (from mold bran) were added to sterile rice flour, thoroughly mixed with the addition of required amount of sterile distilled water and the dough was divided into small balls. The balls were flattened, placed in a sterile petri plate, incubated at 30 ${ }^{\circ} \mathrm{C}$ for 3 days and dried at $40{ }^{\circ} \mathrm{C}$ for $24 \mathrm{hr}$.

Fermentation of finger millet: Finger millet (Eleusine coracana) (brown variety) was cleaned, dehusked, winnowed and washed with water. The millet was steeped in water for two hours, washed again, cooked for $20 \mathrm{~min}$ at $121{ }^{\circ} \mathrm{C}$, and cooled to room temperature. Defined fermentation starter (prepared from rice using pure cultures of $S$. cerevisiae and R. oryzae) was mixed to the cooked millet at the rate of $1 \%(\mathrm{~m} /$ $\mathrm{m})$, and kept for 2 days at $30^{\circ} \mathrm{C}$ for bio-mass development (aerobic fermentation). For solid-state fermentation, the biomass developed millet was tightly packed into plastic containers whereas for semi-solid state fermentations, millet was filled into plastic containers and previously boiled and cooled water was added to the containers at the rate of $50 \%$ and $100 \%(\mathrm{v} / \mathrm{m})$ for semi-solid ${ }_{1}$ and semi-solid fermentations respectively. All containers were then capped tightly and kept at $28 \pm 1^{\circ} \mathrm{C}$ for 15 days for alcoholic fermentation.

Preparation of millet Jand: For the preparation of millet Jand, 1.5 parts (by vol) of previously boiled and cooled water was added to each part (by wt) of biomass developed millet used for alcoholic fermentation. In the case of semi-solid fermented millet, the volume of water added previously during the start of alcoholic fermentations was subtracted from that of total volume of water to be added. The mixture was gently macerated, allowed to stand for $20 \mathrm{~min}$ and strained through muslin cloth with gentle pressing. The Jand (millet beers) so obtained were subjected to chemical and organoleptic analyses.

Analytical procedure: Total soluble solids (TSS) was determined by using hand refractometer $\left(0-32^{\circ} \mathrm{Bx}\right.$, Hanna Instrument, Portugal) and alcohol content was determined by visible spectrometric dichromate oxidation method (Metertek SP-870, Spectrophotometer, Metertech Inc., Taiwan) as described by Zoecklein et al., (1997). The $\mathrm{pH}$ was determined using portable digital $\mathrm{pH}$ meter (Hanna Instrument, Portugal). Total, fixed and volatile acidities and ester contents were determined as per Kirk and Sawyer (1991). Reducing sugar was determined by Nelson-Somogyi method as per Sadasivam and Manickam (1996). Moisture content was determined by oven drying method according to Ranganna (1986).

Sensory evaluation: Sensory evaluation of the millet brew (Jand) was performed using Hedonic Rating Test as per Ranganna (1986). Ten semi-trained panelists were asked to evaluate the products in terms of color, taste and smell on a scale of nine-points ranging from "Dislike extremely" (1) to "Like extremely" (9).

Statistical analysis: The experiment was conducted in Complete Randomized Design (CRD) with three replications. The experimental data were analyzed using one-way ANOVA as per Buysse et al., (2007) at 5\% level of significance and the means were compared by LSD method.

\section{Results and Discussion}

The effects of solid and semi-solid state fermentations using defined fermentation starter on the physico-chemical quality of millet Jand were analyzed and the results are shown in Table 1.

Table 1. Effect of semi-solid fermentation on the chemical characteristics of finger millet Jand.

\begin{tabular}{llll}
\hline \multirow{2}{*}{ Parameters } & \multicolumn{3}{c}{ Values $^{*}$} \\
\cline { 2 - 4 } & \multicolumn{1}{c}{ Solid state } & \multicolumn{1}{c}{ Semi-solid $_{\mathbf{1}}$} & \multicolumn{1}{c}{ Semi-solid $_{\mathbf{2}}$} \\
\hline Moisture (\% m/v) & $96.33^{\mathrm{a}}(1.07)$ & $96.21^{\mathrm{a}}(0.18)$ & $96.28^{\mathrm{a}}(0.23)$ \\
Total soluble solids $\left({ }^{\circ} \mathrm{Bx}\right)$ & $3.27^{\mathrm{a}}(0.06)$ & $3.87^{\mathrm{b}}(0.23)$ & $4.03^{\mathrm{b}}(0.06)$ \\
$\mathrm{pH}$ & $4.17^{\mathrm{a}}(0.12)$ & $3.83^{\mathrm{b}}(0.23)$ & $3.37^{\mathrm{c}}(0.12)$ \\
Total acidity, as lactic acid $(\% \mathrm{~m} / \mathrm{v})$ & $0.33^{\mathrm{a}}(0.01)$ & $0.72^{\mathrm{b}}(0.01)$ & $1.24^{\mathrm{c}}(0.01)$ \\
Fixed acidity, as lactic acid, $(\% \mathrm{~m} / \mathrm{v})$ & $0.26^{\mathrm{a}}(0.02)$ & $0.50^{\mathrm{b}}(0.001)$ & $1.00^{\mathrm{c}}(0.01)$ \\
Volatile acidity, as acetic acid $(\% \mathrm{~m} / \mathrm{v})$ & $0.048^{\mathrm{a}}(0.03)$ & $0.143^{\mathrm{b}}(0.001)$ & $0.156^{\mathrm{b}}(0.002)$ \\
Alcohol $(\% \mathrm{v} / \mathrm{v})$ & $6.20^{\mathrm{a}}(0.72)$ & $7.13^{\mathrm{a}}(0.3)$ & $6.91^{\mathrm{a}}(0.17)$ \\
Reducing sugar as dextrose, $\% \mathrm{~m} / \mathrm{m}$ & $1582^{\mathrm{a}}(128.10)$ & $71^{\mathrm{b}}(6.50)$ & $69^{\mathrm{b}}(5.10)$ \\
Esters, as ethyl acetate $(\mathrm{mg} / 100 \mathrm{ml})$ & $10.60^{\mathrm{a}}(0.90)$ & $13.30^{\mathrm{b}}(0.70)$ & $18.50^{\mathrm{c}}(0.40)$ \\
\hline
\end{tabular}

* Means followed by different superscripts in a row are significantly different $(p<0.05)$ by LSD. Figures in the parentheses are standard deviations. Semi-solid ${ }_{1}$ and Semi-solid ${ }_{2}$ are the semi-solid state fermentations using $50 \%$ and $100 \%$ water addition respectively to biomass developed millet during alcoholic fermentation. 
Semi-solid state fermentation showed significant effects $(\mathrm{p}<0.05)$ on the total soluble solids (TSS), $\mathrm{pH}$, acidities, ester and reducing sugar contents of the finger millet Jand (millet brews) whereas alcohol and moisture contents were not affected. The average moisture contents of millet Jand prepared by solid- and semi-solid state fermentations lied in the range of 96.21 to $96.33 \%(\mathrm{~m} / \mathrm{v})$ and the values were not significantly different $(\mathrm{p}>0.05)$ from each other. TSS values were $3.27,3.87$ and $4.03{ }^{\circ} \mathrm{Bx}$ for solid state, semi-solid ${ }_{1}$ and semi-solid 2 fermented Jand respectively. Semi-solid fermentations incurred significantly higher TSS compared to control (solid state); however, the values between semi-solid fermentations were not different. The $\mathrm{pH}$ values decreased with increasing water addition and the values were significantly different from one another. Semi-solid fermentations significantly increased $(\mathrm{p}<0.05)$ the total acidity contents of millet brews compared to control. Millet fermented with 50\% water addition had more than 2-fold total acidity than that of solid-state fermented one. Similarly, increasing water level increased the fixed acidity of millet Jand. Furthermore, every $50 \%$ increase in water addition nearly doubled the fixed acidity in the millet brew. The volatile acidity of millet Jand prepared by semi-solid state fermentations were significantly higher compared to control, whereas the values between semi-solid fermentations did not differ significantly. From Table 1, it can be envisaged that semi-solid fermentation had a profound effect on volatile acidity than those of total and fixed acidities.

The alcohol contents in the Jand prepared from solid, semisolid $_{1}$ and semi- solid 2 fermentations were 6.2, 7.13 and $6.91 \%$ (v/v) respectively, but the values were not statistically different. Reducing sugar contents decreased with increase in water addition during alcoholic fermentation. Solid-state fermented Jand contained higher reducing sugar than those of semi solid and semi solid $_{2}$ fermented ones, however, the values between the later two were not significantly different. The lower reducing sugar contents in semi-solid fermentation could not be explained owing to the lack of relevant information. The ester contents were 10.6, 13.3 and $18.5 \mathrm{mg} /$ $100 \mathrm{ml}$ Jand prepared by solid, semi solid ${ }_{1}$ and semi solid ${ }_{2}$ fermentations respectively and the values were significantly different from each other.

Due to the lack of relevant information, the results of this study could not be compared. However, similar result of alcohol content $(6.8 \% \mathrm{v} / \mathrm{v})$ but higher values $\mathrm{pH}$ and total acidity were reported by Subba, (1985) in traditionally prepared millet Jand. According to Mongar (2001), the pH, total acidity $(\% \mathrm{~m} / \mathrm{v}$ as lactic acid), reducing sugar $(\% \mathrm{~m} / \mathrm{v}$ as dextrose $)$ and alcohol $(\% \mathrm{v} / \mathrm{v})$ contents in millet Jand fermented by using Murcha were 4.5, 0.6, 1.52 and 4.03 respectively. The $\mathrm{pH}$ and reducing sugar contents seemed comparable, but the acidity was quite high and alcohol content was low than that of solid-state fermented millet samples of this study. Osti (2004) found similar alcohol content $(6.68 \% \mathrm{v} / \mathrm{v})$ in millet Jand fermented by using starter made from Rhizopus and Saccharomyces spp. Cai and Nip (1990) reported analogous effect of semisolid state fermentation on glucose in taro fermentation using starter containing R. tankinensis, $R$. oryzae, $R$. chinensis and $S$. cerevisiae, but contrary to our finding, they reported a significantly higher yield of alcohol in semisolid fermentation than that of solid state fermentation. Similar results of $\mathrm{pH}$, and total acidity, but a lower value of alcohol $(4.8 \%, \mathrm{v} / \mathrm{v})$ in traditionally prepared Jand was also reported by Thapa and Tamang (2004).

Sensory evaluation of millet Jand: Millet Jand prepared by solid and semi-solid state $\left[50 \%\right.$ water addition, $\left(\right.$ semi-solid $\left._{1}\right)$ and $100 \%$ water addition (semi-solid ${ }_{2}$ )] fermentations were subjected to sensory evaluation in terms of color, taste and smell using nine points hedonic method and the results are depicted in Figure 1. Statistical analysis revealed that semisolid fermentation had a significant effect on the organoletpic properties of the millet Jand. Mean sensory scores for taste were found to be 8.4, 7.2 and 6.2 for solid, semi-solid ${ }_{1}$ and semi- solid ${ }_{2}$ fermented samples respectively. Increasing water level decreased the taste preference and the scores were statistically different from each other. Higher acidity seemed to have a negative effect on the taste preference. The taste preference of the Jand prepared by solid, semi-solid ${ }_{1}$ and semi-solid fermentations were rated as "Liked very much", "Liked moderately" and "Liked slightly" by the panelists.

The average color preference scores were 8.4, 7.4 and 7.2 for Jand prepared by solid, semi-solid 1 and semi-solid fermentations respectively. Solid state fermentation produced significantly better colored Jand compared to semi-solid ones while the mean color scores between semi-solid fermented samples were not significantly different. Millet Jand prepared by solid state fermentation was "Liked very much" whilst those prepared by semi-solid fermentation were "liked moderately" by the panelists based on color preference. The mean scores for smell were 8.2, 7.7 and 6.8 for Jand prepared by solid, semi-solid ${ }_{1}$ and semi-solid ${ }_{2}$ respectively. The smell scores between solid and semi-solid did not differ but those between solid and semi-solid 2 and between semi-solid ${ }_{1}$ and semi-solid 2 were significantly different. Although esters are responsible for the smell of the alcoholic beverages, higher contents are thought to be detrimental to the smell. Hence,

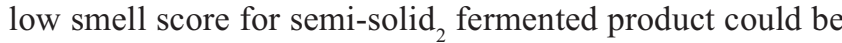
due to the presence of higher ester content (Table 1). 
Solid Semi-solid1

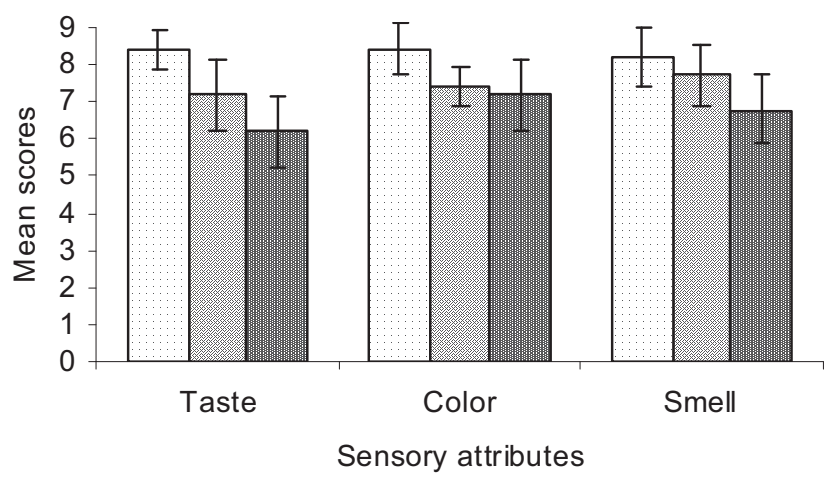

Figure 1. Effect of semi-solid state fermentation on the sensory quality of millet Jand

$*$ Means $\pm \mathrm{SD}$, bars having different letters for any quality attributes are significantly different $(\mathrm{p}<0.05)$. Semi-solid and $\mathrm{Semi}-$ solid $_{2}$ are the semi-solid state fermentations using 50\% and $100 \%$ water addition respectively to biomass developed millet during alcoholic fermentation.

Semi-solid state fermentations unacceptably increased the acidity resulting in substantial lowering in the taste, color and smell preference of the millet beer over the control (solid state fermentation). Alcohol content, one of the most important parameters of alcoholic beverages, was not significantly improved by semi-solid fermentations of finger millet. Moreover, semi-solid fermentation incurred a substantial increase in the ester content in the final product, which was beyond the acceptable limit as judged by the panelists. Hence, solid state fermentation could be regarded as the best method of finger millet fermentation than that of semi-solid fermentation.

\section{Conclusion}

Except moisture and alcohol contents, semi-solid fermentation had a significant effect on the chemical and organoleptic qualities of millet Jand. Substantial increase in TSS; total, fixed and volatile acidities, and ester contents occurred in semi-solid fermentation compared to solid state. Taste, color and smell of the product were largely impaired by semi-solid fermentation with profound impact on taste. No remarkable improvement on the overall quality of the finger millet Jand was found using semi-solid fermentation over solid state one.

\section{References}

Achi O.K. (2005). The potential for upgrading traditional fermented food through biotechnology. African $J$ Biotenhnol., 4(5): 375-380.

Bhandari S. (1997). Comparative study on Raksi production from different raw materials using Murcha and pure cultures, B. Tech (Food) Dissertation, Central Campus of Technology, T.U., Nepal.
Buysse W., Stern R., Coe R. and Matere C. (2007). Genstat Discovery Edition 3 for everyday use. ICARF Nairobi, Kenya.

Cai T. and Nip W-K. (1990). Biochemical changes in the development of alcoholic

fermented product from taro (Colocasia esculenta (L.) Schott]. Trop Sci., 30: 379-390.

Dung N. T. P., Rombouts F. M. and Nout M. J. R. (2007). Characteristics of some traditional Vietnamese starchbased rice wine traditional fermentation starter $(\mathrm{Meu})$. LWT, 40: 130-135.

Karki D. B. and Kharel G. P. (2007). Fermentation starters used in the preparation of traditional cereal based alcoholic beverages. Foodwave, NEFSTA 4: 7-8.

Kirk R. S. and Sawyer R. (1991). Pearson's Composition and Analysis of Foods, $9^{\text {th }}$ edn. Addison Wesley Longman Ltd., Edinburgh Gate, Harlow, England.

Mongar G. N. (2001). Preservation of strained Jand by pasteurization. B. Tech (Food) Dissertation, Central Campus of Technolo, T.U., Nepal.

Odufa S. A. (1985). African fermented foods. In: Wood, B.J.B (Ed) Microbiology of Fermented Foods, Vol.2. Elsevier Appl. Sci. Publ., London, pp 155-191.

Osti S. C. (2004). Saccharification of finger millet using mold Koji. B. Tech (Food) Dissertation, Central Campus of Technolo, T.U., Nepal. 
Rajbhandari L. (1999). Efficiency of alcohol fermentation of Hordeum vulgare (naked barley) from traditional Murcha. M.Sc. Thesis. Central Department of Microbiology, T.U., Nepal.

Ranganna S. (1986). Handbook of Analysis and Quality Control of Fruits and Vegetable Products, $2^{\text {nd }}$ Edn. Tata McGraw-Hill Publishing Company, Ltd., New Delhi, India.

Sadasivam S. and Manickam A. (1996). Biochemical Methods. $2^{\text {nd }}$ edn., New Age International (P) Limited Publishers, New Delhi, India.

Subba C. (1985). Raksi production from finger millet (Kodo) by traditional method. B. Tech (Food) Dissertation, Central Campus of Technolo, T.U., Nepal.

Thapa S. and Tamang J. P. (2004). Product characterization of Kodo ko Jaanr: fermented finger millet beverages of the Himalays. Food Microbiol., 21: 617-622.

Upadhyaya A. (2005). Effect of raw materials on the quality of Jand. . B. Tech (Food) Dissertation, Central Campus of Technolo, T.U., Nepal.
Venkataramu K. and Basappa S. C. (1993). A comparative study of 'Chhang' fermentation from Ragi using natural (traditional) and pure microbial inocula. IFCON, (1993). Poster Session Abstract, AFST (I)

Verma S. (1991). Study on the preparation and efficacy of starter cake prepared from A. oryzae and S. Sake using rice as binder. B. Tech (Food) Dissertation, Central Campus of Technology, T.U., Nepal.

Yoon S. S. (1993). ChenMin Yo Sul: A Translation of Chi-MinYao-Shu in Korea. MinEumSa, Seoul, Korea. In: Fermented Cereals: A Global Perspective. FAO Agricultural Services Bulletin No. 38. Food and Agriculture Organization of the United Nations, Rome (1999), pp 74.

Zoecklein B.W., Fugelsang K. C., Gump B. H and Nury F. S. (1997). Wine analysis and production. CBS Publishers and Distributors, New Delhi, India. 